\title{
Article \\ On the Impact of Additive Manufacturing Processes Complexity on Modelling
}

\author{
Panagiotis Stavropoulos*D, Panagis Foteinopoulos and Alexios Papapacharalampopoulos \\ Laboratory of Manufacturing Systems and Automation, Department of Mechanical Engineering and Aeronautics, \\ University of Patras, 26504 Patras, Greece; pfotein@lms.mech.upatras.gr (P.F.); \\ apapacharal@lms.mech.upatras.gr (A.P.) \\ * Correspondence: pstavr@lms.mech.upatras.gr; Tel.: +30-2610-91-01-60
}

check for updates

Citation: Stavropoulos, P.;

Foteinopoulos, P.;

Papapacharalampopoulos, A. On the Impact of Additive Manufacturing Processes Complexity on Modelling. Appl. Sci. 2021, 11, 7743. https:// doi.org/10.3390/app11167743

Academic Editor: Radu Godina

Received: 12 June 2021

Accepted: 20 August 2021

Published: 23 August 2021

Publisher's Note: MDPI stays neutral with regard to jurisdictional claims in published maps and institutional affiliations.

Copyright: (c) 2021 by the authors. Licensee MDPI, Basel, Switzerland. This article is an open access article distributed under the terms and conditions of the Creative Commons Attribution (CC BY) license (https:/ / creativecommons.org/licenses/by/ $4.0 /)$.

\begin{abstract}
The interest in additive manufacturing (AM) processes is constantly increasing due to the many advantages they offer. To this end, a variety of modelling techniques for the plethora of the AM mechanisms has been proposed. However, the process modelling complexity, a term that can be used in order to define the level of detail of the simulations, has not been clearly addressed so far. In particular, one important aspect that is common in all the AM processes is the movement of the head, which directly affects part quality and build time. The knowledge of the entire progression of the phenomenon is a key aspect for the optimization of the path as well as the speed evolution in time of the head. In this study, a metamodeling framework for AM is presented, aiming to increase the practicality of simulations that investigate the effect of the movement of the head on part quality. The existing AM process groups have been classified based on three parameters/axes: temperature of the process, complexity, and part size, where the complexity has been modelled using a dedicated heuristic metric, based on entropy. To achieve this, a discretized version of the processes implicated variables has been developed, introducing three types of variable: process parameters, key modeling variables and performance indicators. This can lead to an enhanced roadmap for the significance of the variables and the interpretation and use of the various models. The utilized spectrum of AM processes is discussed with respect to the modelling types, namely theoretical/computational and experimental/empirical.
\end{abstract}

Keywords: additive manufacturing; simulation; path planning; modeling; head speed

\section{Introduction}

In additive manufacturing (AM) processes, parts are created in a layer-by-layer fashion by selectively fusing the material of the current layer on that of the previous one, based on information provided by 3D model data [1]. In 1981, Dr. Hideo Kodama came up with the rapid prototyping idea, while in 1984, Chuck Hull filed his patent for his stereolithography apparatus [2]. AM differs from rapid prototyping [3] in that it specifically aims to manufacture end-user parts, rather than just prototypes [4]; its first application took place on 1999 for the creation of a scaffold for a human bladder [5]. In 2006, the first metal-AM application was made commercially available in the form of selective laser sintering. The interest in AM processes has been steadily increasing in the past years [6]; according to estimations, it will soon exceed 5\% of the total global market [7], leading to a \$667 million of added value produced exclusively using AM [8]. One of the most important advantages of AM is the manufacturing freedom it offers [9], rendering part complexity nearly cost free. This complexity-related cost is similar to what is known as the penalty of change; a change in the part design due to customization results in some additional costs, depending on the flexibility of the manufacturing process [1]. In the case of additive manufacturing, this cost is very close to zero, as it requires no additional tools. The overall cost, however, is a much more complicated issue, as the whole lifecycle of the part as well as that of the machine tool are implicated [10] and is of course case dependent [11]. This freedom in design has a 
direct impact on many industrial sectors, as well as in part designs [12]. In addition, AM is viable in terms of cost production of small batch sizes, even of one part, paving the way for mass customization of products [6]. Moreover, these processes are environmentally and ecologically promising in terms of material and energy consumption [9]. A classification of the existing AM processes is summarized in Table 1 [13] according to (ISO 17296-2) [14].

Table 1. Classification of additive manufacturing (AM) processes (according to [14]).

\begin{tabular}{ll}
\hline \multicolumn{1}{c}{ AM Process Group } & \multicolumn{1}{c}{ Typical Commercial Names } \\
\hline Vat Photopolymerization (VP) & $\begin{array}{l}\text { Stereolithography (SLA), Digital Light Processing, Solid Ground Curing, Projection } \\
\text { Stereolithography }\end{array}$ \\
& $\begin{array}{l}\text { Electron Beam Melting (EBM), Electron Beam Additive Manufacturing (EBAM), } \\
\text { Selective Laser Sintering (SLS), Selective Heat Sintering, Direct Metal Laser Sintering } \\
\text { Powder Bed Fusion (PBF) }\end{array}$ \\
& (DMLS), Selective Laser Melting (SLM), Laser Beam Melting (LBM) \\
& Laser Metal Deposition (LMD), Direct Metal Deposition (DMD), Direct Laser Deposition \\
& (DLD), Laser Engineered Net Shaping, Electron-Beam Freeform Fabrication, Weld-based \\
Directed Energy Deposition (DED) & Additive Manufacturing \\
& Powder Bed and inkjet Head, Plaster-based 3D Printing \\
Binder Jetting (BJ) & Fused Deposition Modeling (FDM), Fused Filament Fabrication \\
Material Extrusion (ME) & Multi-Jet Modeling, Aerosol Jet, Ballistic Particle Manufacturing, Drop On Demand \\
& (DOD), Laser-Induced Forward Transfer, Liquid Metal Jetting (LMJ), Multi-Jet-Printing \\
Material Jetting (MJ) & (MJP), Nano Metal Jetting, NanoParticle Jetting, Polyjet, Printoptical Technology \\
& Laminated Object Manufacturing (LOM), Ultrasonic Consolidation \\
Sheet Lamination (SL) & Cement AM/3D Printing, Concrete AM/3D Printing \\
AM for the Construction Sector &
\end{tabular}

As observed, in AM, there are several different process mechanisms, machine types, and materials, including plastics, metals, composites [15], biomedical, and cement-based materials [16]. Subsequently, within the wide range of challenges (as indicatively shown in [17]), part quality is of the utmost importance [17-21], as mentioned in literature [18]. Various models are used to predict the final part quality and, as a matter of fact, they could achieve this even in computational times comparable to the process cycle time [22]. Besides, the diversified process parameters encountered in the plethora of the mechanisms, as well as the movement of the head are of major importance for the process, as they directly affect build time, strength and dimensional accuracy of the part [22]. However, in the majority of existing studies, processes are usually simulated either throughout a very short portion of the manufacturing time or at very small parts [23-28]. It remains, however, a fact that knowledge of the entire progression of the phenomenon is key for the optimization of the parameters of the process [29], as summarized in Figure 1.

A unified approach in additive manufacturing towards metamodeling is not considered to be straightforward, since there is a plethora of mechanisms as aforementioned. However, in general, the challenges that are adjacent to AM are easy to be classified into technical, capability-related, financial, design and IT-integration-related [30], which resembles the classification from the design point of view [31]. The technical ones could be classified into four sub-categories [18]: process related, people related, raw material related and machine related. It is noted, though, the process and the machine related challenges are interrelated, since the delivery of the energy and/or the material are done by mechatronic systems [32]. The benefits, both per process and in general, have also been pinpointed by Deloitte in the aforementioned study; complexity of the part, time to market, cost reduction (in the strict sense of inventory minimization), customization, and eco-friendliness are some key features of AM, regardless of the mechanism. Additional benefits and challenges of a hybrid nature (both technical and business) can be found in other works in the literature, such as the tabular presentation of Ford and Despeisse [33], where even aspects like localized material recycling are mentioned, while per process, the generic features are well documented [34]. Another interesting classification of the technical issues come across in literature has been the $4 \mathrm{M}^{\prime} \mathrm{s}$, where the making, the material, the metrology as well as the market are mainly regarded [35]. This particular approach 
can help also as regards the material properties and hence the mechanisms that are present in industrial AM. This has a direct impact on industrial systems metamodeling, as from the cyber-physical system point of view the mechanism and the subsystems are of utmost importance [36]. Meanwhile, in the performance prediction through modelling, the key aspect is indeed the identification of the main mechanisms (process- and machinewise) [37]. As a matter of fact, Michopoulos et al. [38] indicate five domains of modules; Energy deposition, motion control, stock feeder, material and geometry, while at the same time they discuss behavior at macro, meso and micro level ( $3 \mathrm{~m}$ 's). Thus, as one may be interested in studying in a unified matter the various mechanisms that there are available, a specific schematic (Figure 2, left diagram) could be created, in order for the conceptual modelling to be conducted. Then, a Bayesian network [39] could be used to elaborated quantification of the features. However, before this aspect, a more quantified approach for conceptual modelling could be elaborated. This is depicted in the right diagram of Figure 2, adopting the abstract notation of unified modeling language (UML), a general purpose modelling language providing the visualization of the design of a system [40]. In this case, the involved entities are engaged in an one-to-many relationship (denoted as $\left.1-1 .{ }^{*}\right)$, i.e., a machine may have more than one heads. This way, all the classifications of benefits and challenges (i.e., $4 \mathrm{Ms}$ and $3 \mathrm{~m}$ 's, above) can be integrated in terms of specific components' features. It is noted that the main focus of this work is on variables involved, thus the listofModels is the most related term.

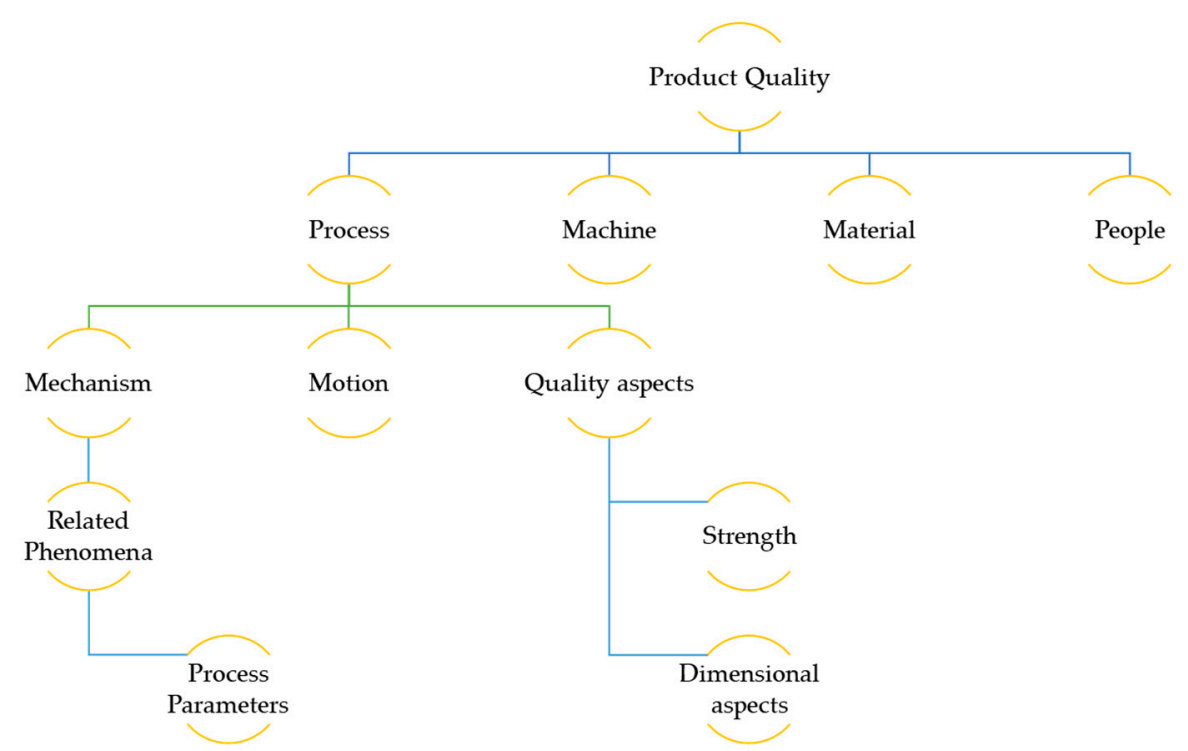

Figure 1. Issues in AM (adapted from [18]).

As proven in literature, there are many attempts to correlate quality issues in particular with modelling aspects, throughout the entirety of the AM processes. For instance, in metal-AM processes and especially on powder bed fusion processes, the investigation of process parameters (input variables-tuned) on the performance indicators (output variables-regulated) depending on the scale of the modelling. Primarily, four multi-scale modelling techniques occur in the literature [41-43], (i) the micro-scale which focuses on the discrete powder level and examine the melt-pool dynamics, (ii) the meso-scale which focuses on continuous powder and study the thermal-field and the melt-pool dimensions, (iii) the macro-scale which aims on the building low volume geometries and investigates the developed thermal- and stress-field and (iv) the part-scale which does not consider a moving printing head, but the heating of upper nodes in equivalent layers (namely flash heating method). An analytical model for the thermal field is constructed by the authors of [44] to predict the quality aspect of density of printed parts, producing the process map of two different alloy materials. Similar to metallic-AM one, the first three scales come upon to SLA [45]. Nevertheless, each one targets different phenomena. For instance, 
the micro-scale of SLA investigates the chemical, thermal and mechanical behavior of resin and the meso-scale focuses on the cured-depth. The macro-scale in both SLM and SLA, explore the thermal expansion of the printing body. An approach to determine the optimal orientation of SLA-fabricated parts is investigated by [46] utilizing parametric finite element method simulations to identify the minimum deformations. In AM for construction purposes such as cement-based AM, mechanical and rheological have to be assessed for adequate bond strength between the layers [47]. A study on 3D-printing of concrete is conducted by [48] to predict the quality aspect of cross-section in matter of layer height and width through computational fluid dynamics (CFD), validating it with experimental results. FDM is another AM process that requires the attention to the quality challenges. In the literature, the authors of [49] consider the adoption of FEA modelling to predict the structural behavior of two test cases. As such, it can be claimed that the complexity introduced by processes mechanism (and consequently by processes modelling) in design and operation phases is quite differentiated among the various processes.
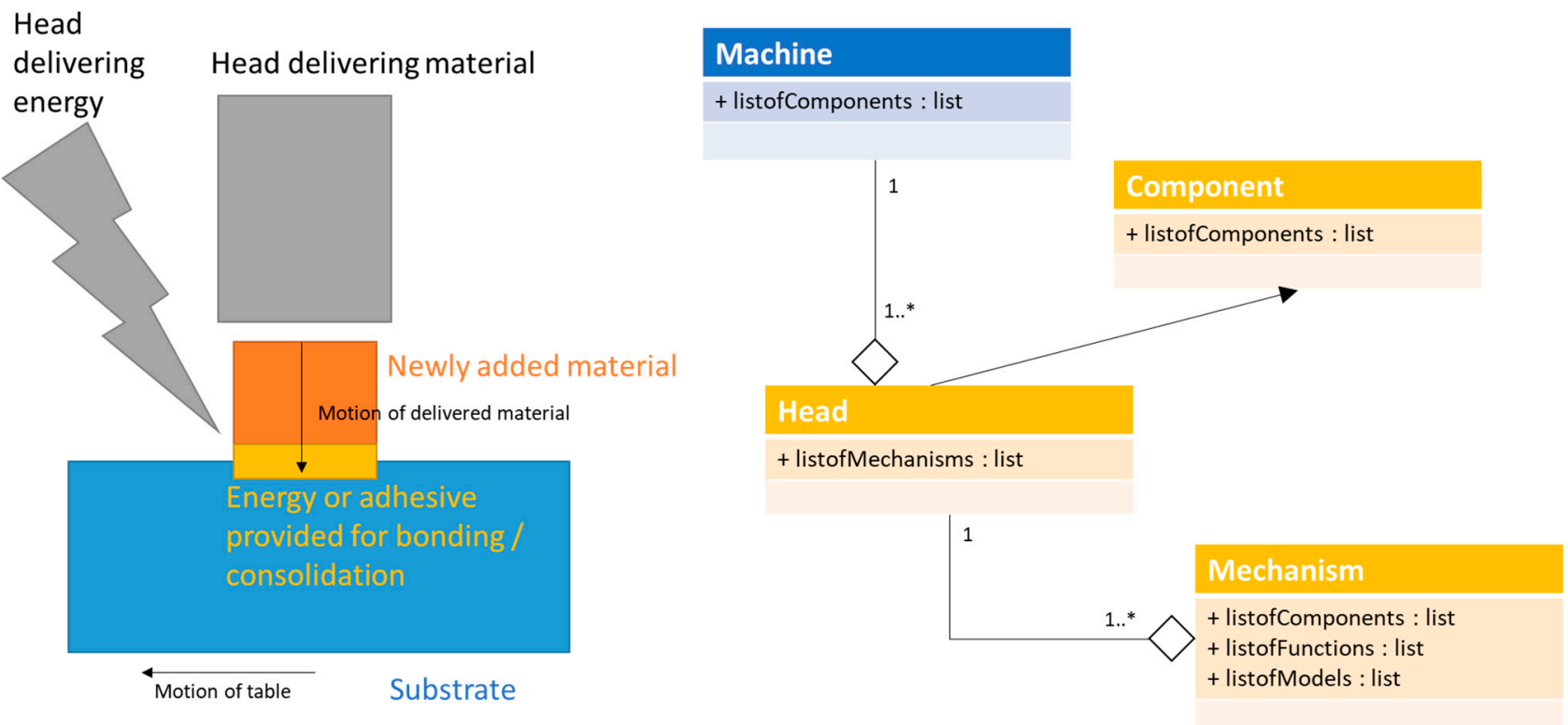

Figure 2. Abstract depiction of AM machine modules (left) and the corresponding abstract modelling using unified modeling language (UML) (right).

From the point of view of standard process planning procedure [50] two major factors are utilized in a process family selection; material properties and production rate (or volumes) [1]. The family of additive manufacturing, however, is pretty much well defined in such a space of two variables; almost all materials are addressed and it regards rather customization, i.e., not high production volumes. To this end, one would need further criteria to proceed with the exact AM selection [51,52]. Also, at the same time, during both the design and operation phases of manufacturing, it is highly desirable to have criteria for modelling the process [53,54] also towards digital twins' inclusion [55]. To this end one would need similar criteria with respect to the process, and potentially the machine [56]. It seems that process mechanism could be described by temperature [57-59] and the product could be represented by its size $[60,61]$. However, the modelling is not included yet as an aspect.

As different AM mechanisms and different models are utilized, it would be helpful to have an overall approach for a holistic metamodeling framework, like the one depicted in Figure 3. This would use the introductory steps of conceptual [62] and mathematical [63] modeling towards forming a model. This model can capture the full effect of all the parameters on the final performance, including the machine that embodies the process [64]. A desired and customizable level-of-detail for the simulations [65] can be used to control 
the predictability of the model. The complexity of the process model, as mentioned, can be a useful term in this procedure, as it captures all the related aspects in a quantified manner. Besides, the Ishikawa diagrams [66], indicating the path of dependences among the involved variables, are a qualitative and complementary version of this approach.

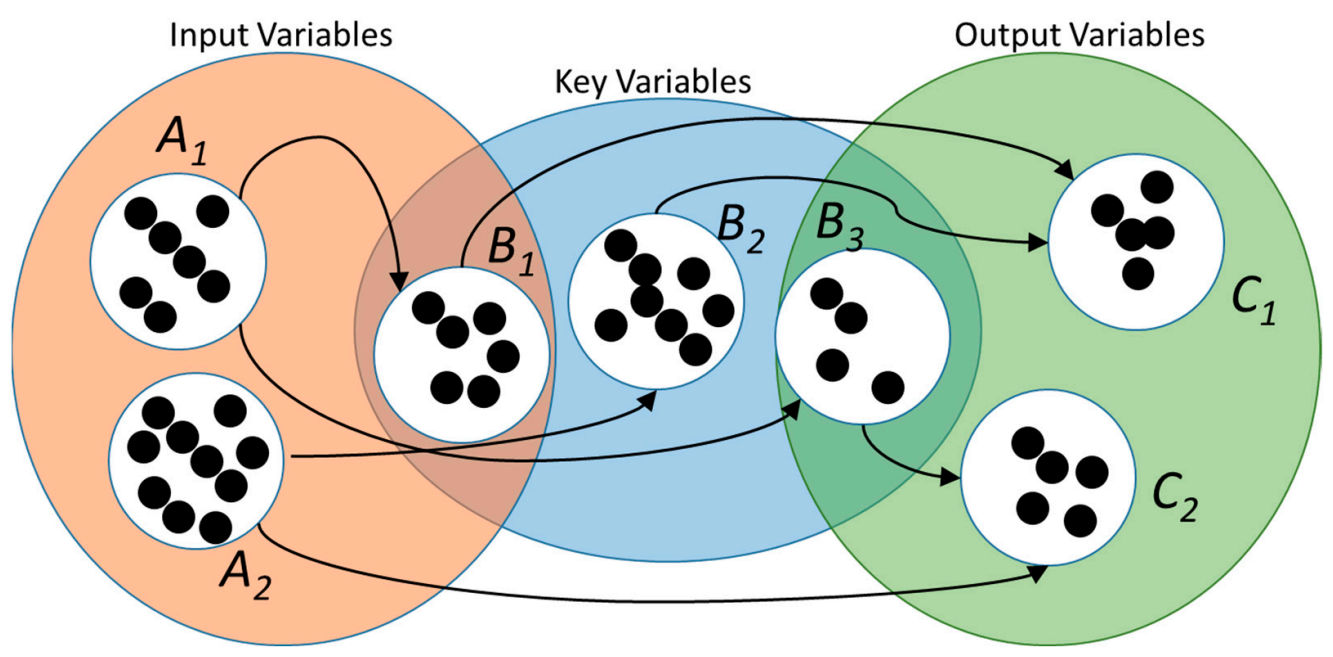

Figure 3. The current meta modelling consideration.

To this end, a roadmap is needed towards selecting the optimal modelling technique. One of the key aspects that will help in this is the efficiency of modelling, however, it seems that there is no unique metric for such a concept (beyond the computational time), as both computational models and empirical ones require their own dedicated time for preparation and solution. Thus, complexity is a key feature that needs to be taken into account; however, the modelling complexity is more than simply stating the interactions between the variables $[67,68]$ or estimating the computational complexity (especially since numerical methods are not considered to be algorithms, albeit there is the related concept of convergence). In the current work, process complexity is considered in terms of modelling complexity and it is measured via the relationship between the process parameters and the performance indicators. It is used under the framework of a metamodeling framework, specifically developed to accommodate this concept. Also, there are some preliminary results that are derived, based on data from previous works and help towards classifying the processes with respect to a complexity scale.

\section{Framework}

The principles of model-based system engineering (MBSE) [69] were taken into account for the development of the framework. According to MBSE, a system model comprises increasing detailed models that are all part of a holistic system model, aiming to "construct a model of a system that we can transform into the real thing" [69]. Complexity is not a straightforward concept $[70,71]$, due to the fact that it is problem-oriented and its definition varies [72]. For sure, the factors that are implicated change with the type of the system. For instance, depending on the (deterministic herein) model used, the following factors affect the complexity:

- Algebraic systems $\mathrm{f}\left(\mathrm{x}_{\mathrm{n}}\right)=0$ : number of variables $n$, form of equations $f$, solvability.

- Dynamic systems $f\left(x_{n}{ }^{\prime}, x_{n}\right)=0$ : number of variables, order of derivatives, form of equations, solvability

- Distributed systems $\mathrm{f}\left(\frac{\partial^{k} x_{n}}{\partial q_{m} k}, x_{\mathrm{n}}\right)=0$ : number of variables, number of independent variables, order of derivatives, form of equations, solvability 
- Control problems $\mathrm{f}\left(\frac{\partial^{k} x_{n}}{\partial q_{n}{ }^{k}}, \mathrm{x}_{\mathrm{n}}, \mathrm{u}_{\mathrm{m}}\right)=0$ : number of variables, number of independent variables $(u)$, order of derivatives, number of inputs, form of equations, solvability, controllability

Focusing on linear systems and considering the control problem in order to frame the quantities needed, the following quantities are indicative of the complexity, given that the equation is reduced to $\sum_{k=1}^{K} \sum_{m=1}^{M} \sum_{n=1}^{N} a_{n, k} \frac{\partial^{k} x_{n}}{\partial q_{m}{ }^{k}}+\sum_{k=1}^{Q} \sum_{m=1}^{M} \sum_{n=1}^{U} a_{n, k} \frac{\partial^{k} u_{n}}{\partial q_{m}{ }^{k}}=0$ could be expressed through a heuristic metric like the following, without taking into account the solvability or the effect of the inputs on output.

- $\quad \mathrm{I}=\log (\mathrm{KMNQU})$

However, this metric is not applicable to process modelling. In particular, the phase change in not represented in such equations without some extra manipulation. Also, it is not inclusive for multi-phenomena modelling. Finally, it regards only straightforward theoretical modelling, i.e., the behavior of the machine tool is not included. To this end, the following four-steps approach of Figure 4 is adopted. The goal is to have an estimation of the interactions complexity among the discretized variables. Hence, the black dots represent the discrete values that each variable may take. The key variables are a newly introduced term that attempts to describe variables deriving from modelling and can have either input, or output, or even neutral character; examples of such variables for the case of SLM are: B1 temporal derivative of temperature, B2 temperature, B3 gradient of temperature. Examples of input variables (or process parameters) can be the laser power and the head (or table) speed and output variables (or performance indicators) can be process time and quality. The graph formed is not indicative of the true relationships.
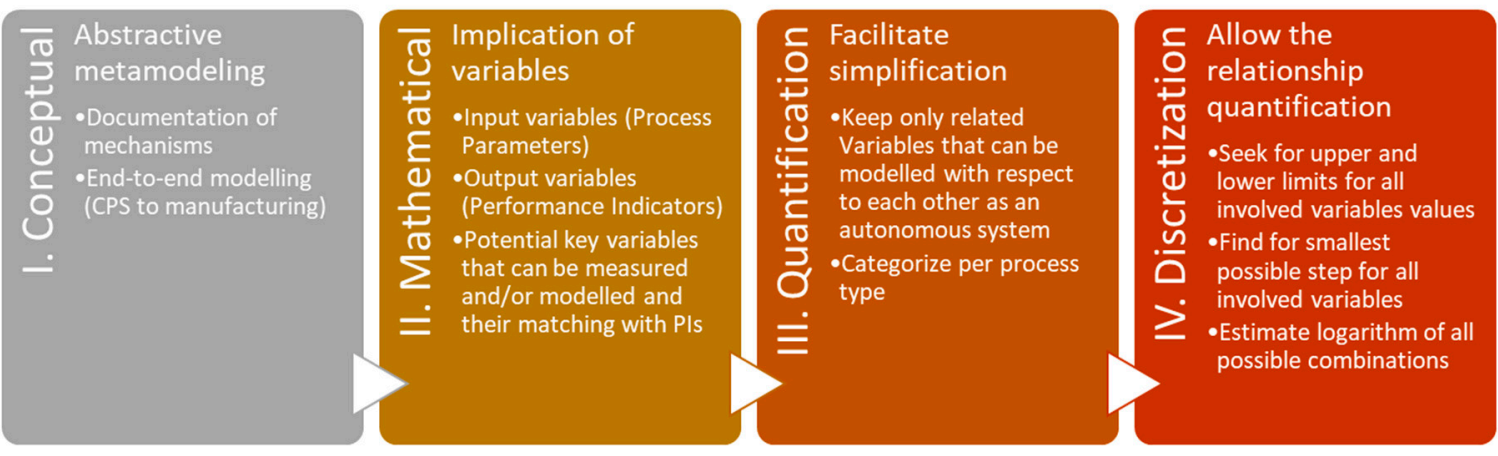

Figure 4. The current meta modelling framework.

The procedure followed to acquire a quantified version of this relationship's complexity is given below in Figure 4. There are four steps, three of which are analyzed below and the fourth one is explicitly applied in the case of AM in the next section. The first three steps are related to acquiring such a relationship and rendering its simplification and its quantification feasible. Hence, they correspond to standard modelling techniques, with simplification in mind as one of the final goals. Also, it has to be mentioned that there is a possibility that the input parameters are not always completely measurable, so they could be eventually replaced by other metrics. For instance, the path configuration itself is not a quantifiable aspect, thus in literature it can be substituted by discrete configurations and intermediate metrics [22,73].

In view of addressing the plethora of different $A M$ processes, the aspects that are finally kept in this metamodeling approach are the process mechanism and its process parameters, as well as the motion of the head related to the part. Also, the quality is the manufacturing attribute [1] that is of interest, implicating a whole family of related key performance indicators. As explained further below, these indicators have to be defined in the next step, based on the process category and the manufacturer's interests. Therefore, one characteristic process of each process group has been selected; SLM has been chosen 
from the metal-based AM processes, FDM was chosen from the plastic-based and SLA from the resin-based ones. Regarding cement-based AM, the process chosen has been that of concrete printing, instead of contour crafting, due to lack of mold [74]. Concerning the temperature of these processes, the process mechanism of the metal-based AM (PBF) demonstrates the highest temperature, followed by that of the plastic-based AM (FDM). Thus, a chart occurs (Figure 5) implicating these concepts through a graph and separating the interlinking entities in four different categories, as below:

1. Software, including a form of input to the process.

2. Hardware, specifying what is being affected directly by the corresponding software.

3. The process characteristic, which mainly consists of motion and bonding; the latter is depending on the process that this procedure is applied on, so candidates underlying mechanisms may be solidification (i.e., in SLM) and polymerization (i.e., in SLM).

4. Manufacturing, containing the corresponding KPIs (that is quality, in the context of the current work).

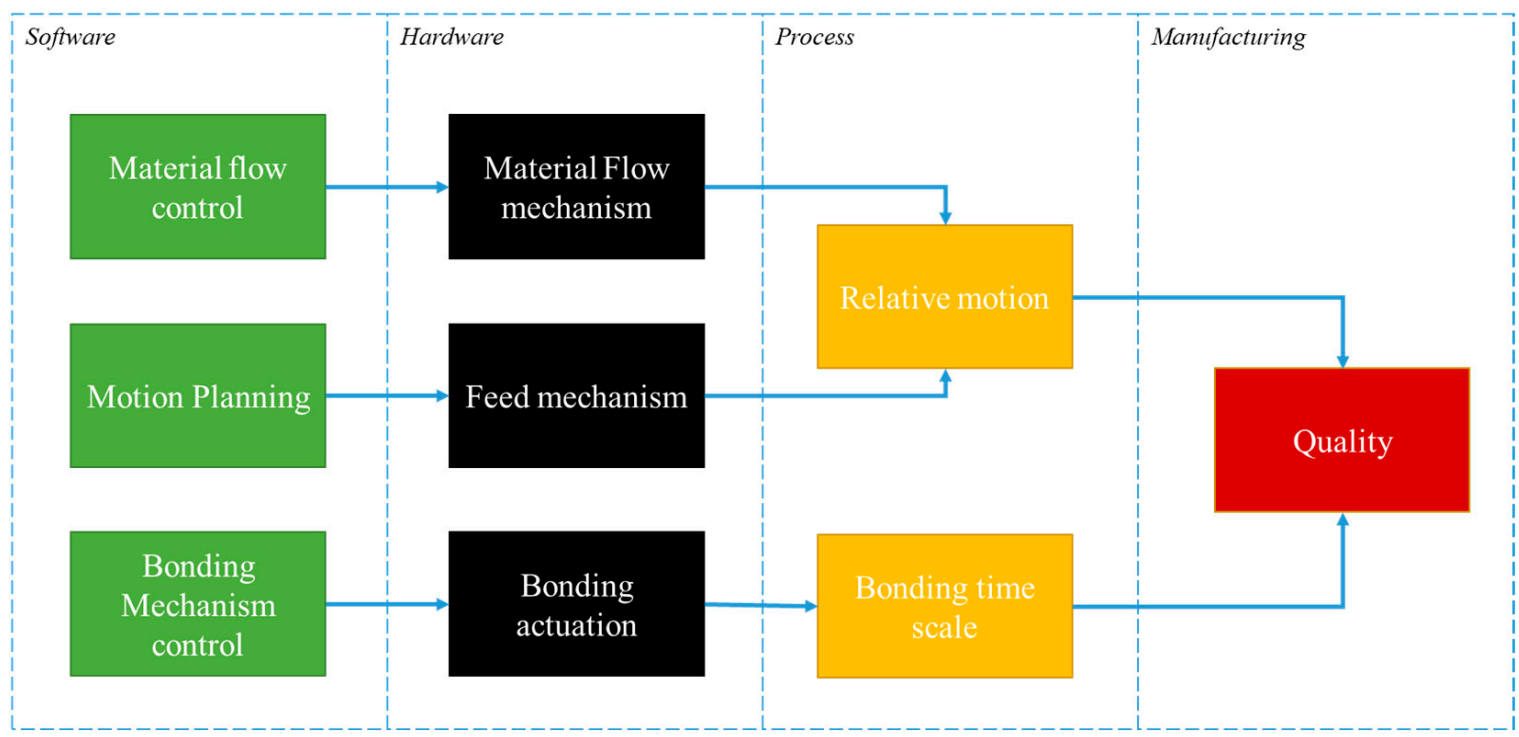

Figure 5. Abstractive metamodeling in AM.

However, this is still an abstract scheme, so it needs to be elaborated and possibly simplified. Thus, the corresponding abstract entities (indicated by the word "software" in Figure 5, implying some sort of control), ought to be transformed into regulated variables, potentially towards quantification. In the meantime, output variables, specifically qualityrelated ones as mentioned in Figure 5, are analyzed into output (Quality) related variable(s), per manufacturing process. Next, the two categories "Hardware" and "Process" are substituted by key variables, also per manufacturing process. This is not a straightforward choice, however, there are more than one aspects that contribute towards justifying the choices in Figure 6, such as literature aspects in modelling and control. As indicated in literature, temperature can be considered such a variable for metals, since it guarantees the solidification (enthalpy is overlooked deliberately for reasons of simplification), while temperature gradient is responsible for stresses formation [22] and temperature's temporal derivative causes defects creation (this may also cover the melt-pool effect on defects, due to enthalpy rate) [75]. As far as the other manufacturing processes are concerned, plastics are reigned once more by temperature [76], resins operate on a power-exposure time basis, so cure depth can be used to simplify that [77] and cement-based additive manufacturing relies on additives for a sufficiently good combination of printability and settling time [21]. 


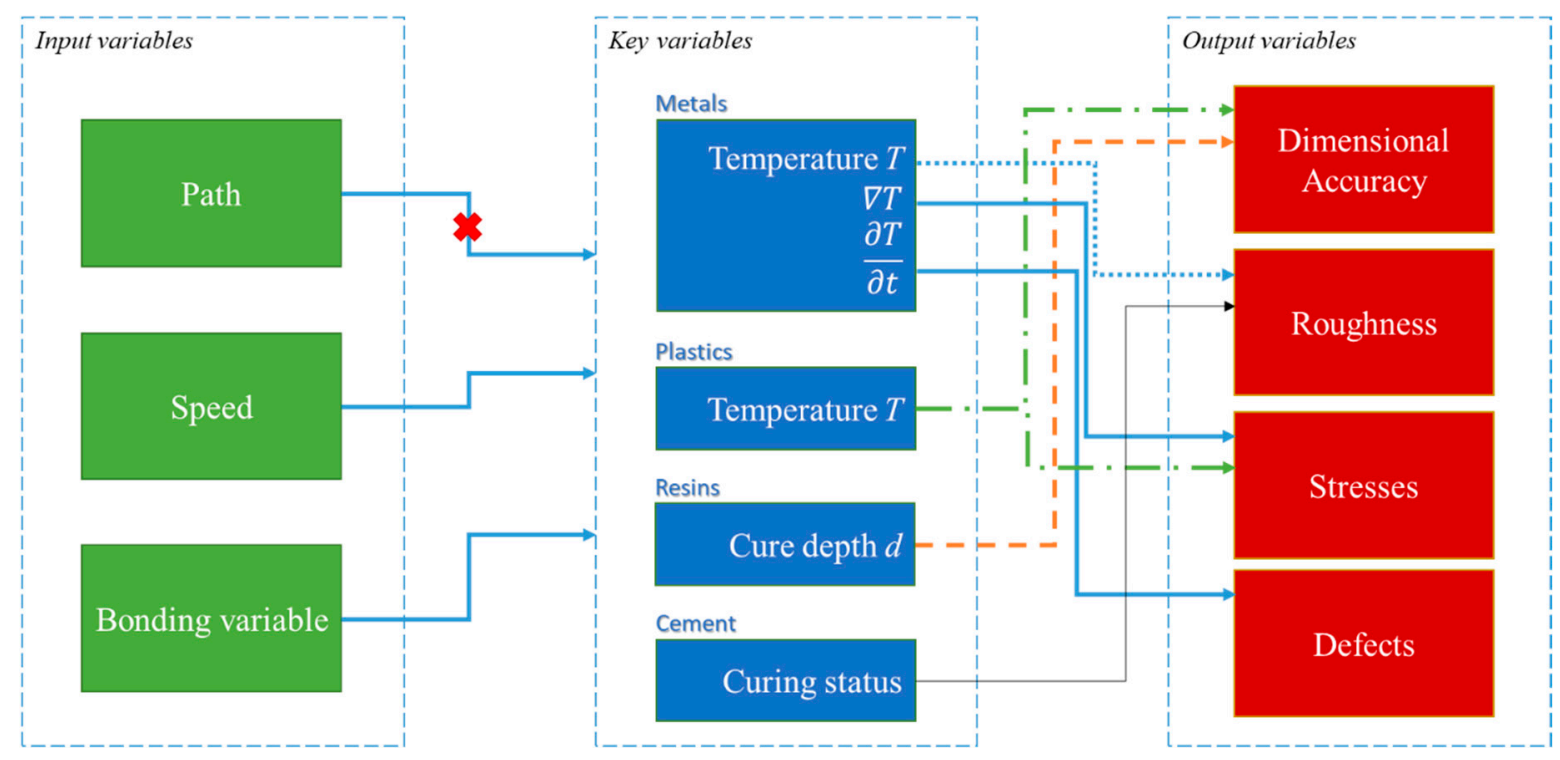

Figure 6. The implication of key variables in metamodeling.

The quality of each process is also different, spanning from simple dimensional inaccuracies to all four indicators of Figure 6. Thus, the impact of the process parameters can be measured based on the variance of the performance indicators $(Q)$, as per Equation (1), adopted from literature [78], with $V$ denoting a bonding key variable and $S$ a motion variable.

$$
I=\frac{\partial Q}{\partial V} \Delta V+\frac{\partial Q}{\partial S} \Delta S,
$$

All in all, this metric can be used to quantify the impact of the variances of process parameters on the quality indicator. Examples of related relationships are shown for the case of metals in Figure 7.

$\operatorname{Tmax}\left({ }^{\circ} \mathrm{C}\right)$

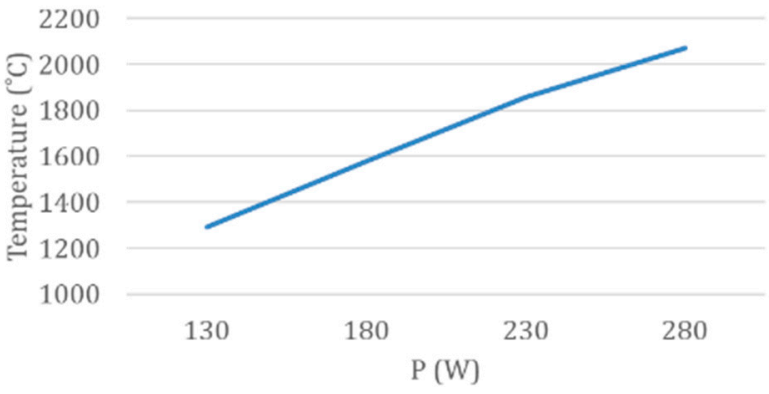

$\operatorname{Tmax}\left({ }^{\circ} \mathrm{C}\right)$

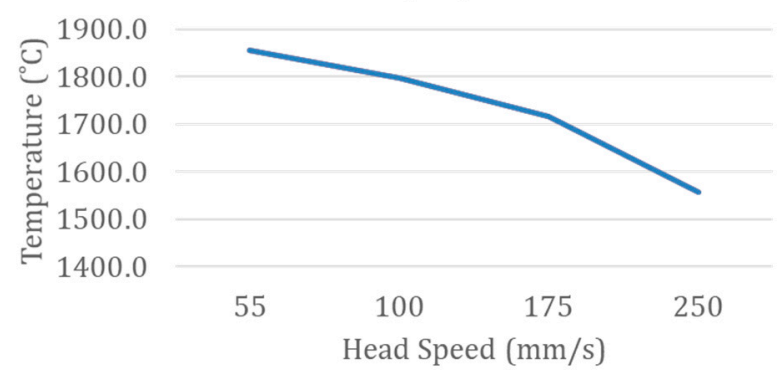

Figure 7. Examples of variables relationships in the case of metals AM.

However, there are some shortcomings in the use of this formula; firstly, the partial derivatives are not known before the models solution and the path is not always characterized by a single variable. Thus, an alternative approach has to be considered, which takes into account the following assumptions:

1. The complexity is an additive metric, thus it should engage logarithms, as in the case of Shannon's entropy [79].

2. Discrete values for each variable are considered. This is a way to ease the computation of the complexity.

3. The size of the search space (combined process parameters (PPs) and key performance indicators (KPIs) space) in a control or an optimization problem is indicative of its complexity. 
4. Laser frequency is neglected as pulsed laser could be considered continuous with reduced power, under specific conditions.

5. Speed is considered to be a control variable, in the sense that it controls the process time and the bonding variable compensates for its effect.

6. All issues related to post-processing are neglected.

7. Path effect can be represented by the gradient of the temperature. This reduces to a high extent the formulation, as path itself is not an easily quantifiable factor.

It is noted that in the case of cement, the geometry of the part here is rather designed for the part, regardless of the process. This means that the geometry of the part serves the function of the part, rather than its buildability, i.e., a bench made of concrete is supposed to be ergonomic and aesthetically pleasant. Therefore, the geometry of the part itself cannot be used for process optimization for the most part, even though several guidelines for the infill geometry can be formally stated [80]. In any case, the form of the path or the head motion are not that useful for optimizing the manufacturing quality explicitly as, firstly, there are no gradients in temperature and, secondly, the consolidation (within a layer) is not an issue, since the setting times are quite high [81].

In the following attempt for rigorous metamodeling, the manufacturing KPIs of cost $(C)$, time $(t)$ and defects $(D)$ are considered. Also, the key variable(s) $(K)$ is taken into consideration, with it being the temperature, or the cure depth or the curing status, depending on the process case. Finally, the speed $(S)$ and the motion profile $(M)$ are regarded. Since $S$ and $M$ are regarded rather as control variables (Equation (2)), it seems that a particular relationship between the outputs and the rest of the variables (Equations (3) and (4)) can be retrieved, significantly simplifying the problem. It is noted that the terms of $\nabla K$ and $\partial K / \partial t$ are indicative of the SLM and FDM cases, but they can be included in an attempt for global metamodeling.

$$
\begin{gathered}
t=q(S, M) \\
C=f_{1}(K ; S, M), D=f_{2}(\partial K / \partial t, \nabla K, K ; S, M) \\
K=g_{1}(P ; M), \nabla K=g_{2}(P ; M), \partial K / \partial t=g_{3}(P ; M)
\end{gathered}
$$

The fact that all issues related to post-processing can be ignored allows us to overlook the temporal derivative of $K$. Then, simply by considering Equation (3) in the sense that they manufacturing metrics could be decoupled from process mechanism complexity, and at the same time considering that the motion results in a set of $K$ gradients, namely $\nabla K=\xi(M)$, one can assume that there is a relationship between the three main variables that are remaining, given that $S$ is completely ignored as it is a control parameter (Equation (5)).

$$
\eta(P, K, \nabla K ; S)=0
$$

For further simplification, the agnostic character of the complexity metric with respect to the form of the equations is also adopted, resulting in considering discrete values of all the implicated variables and considering a link between them. Thus, a kind of probabilistic metric is used for this overall relationship. Entropy seems like a good candidate. The final combination of metrics is presented in Figure 8. Speed is also mentioned there for reasons of completeness, while the discretization will take place in the next section. 


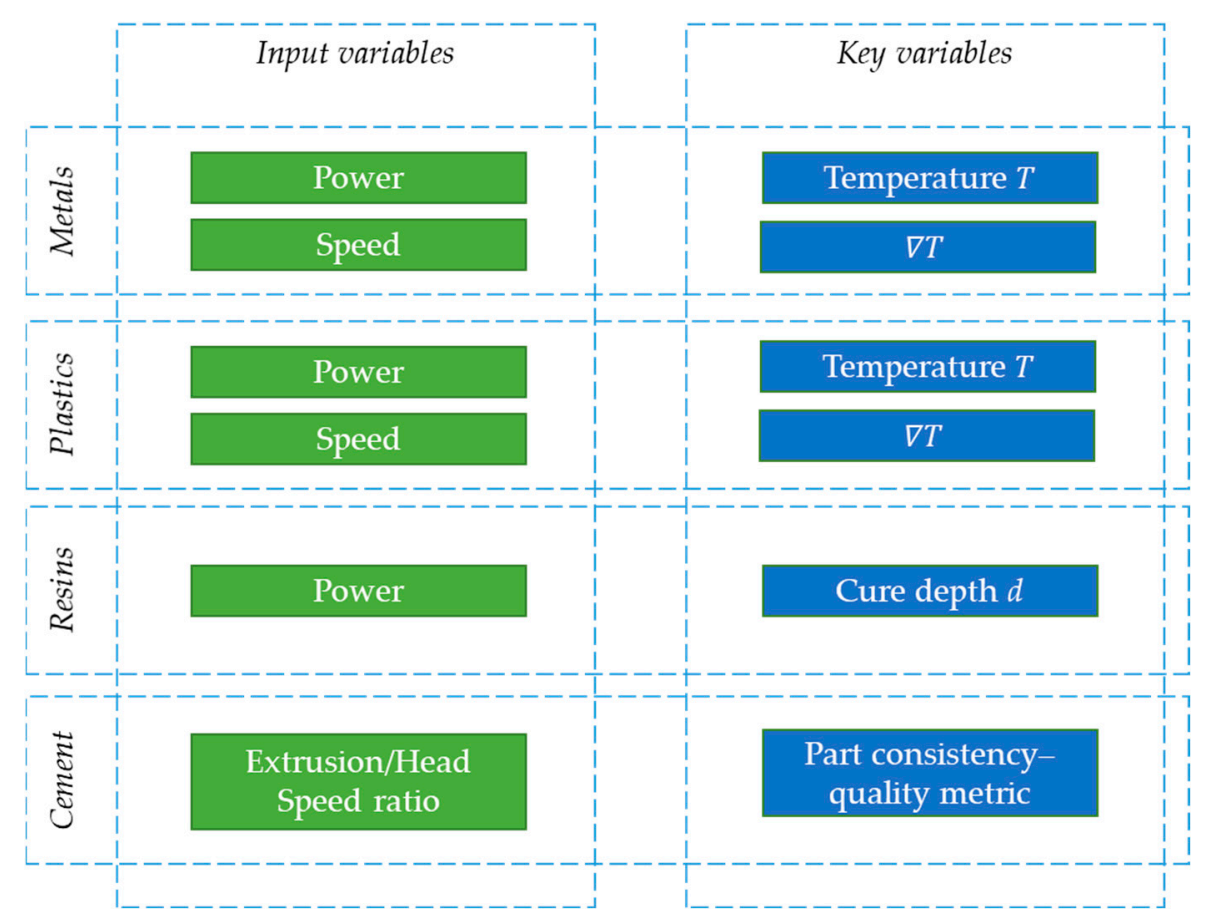

Figure 8. Process variables implicated in the complexity estimation.

\section{Implementation and Primary Results}

The goal of this section is to apply the aforementioned numerically on AM process groups and classify them with respect to their complexity. To this end, the data used here are taken from relevant literature and are applied on the framework that was described above. All the values are summarized in Tables 2 and 3. Therefore, as mentioned in the previous section, regarding the choice of discrete values for the aforementioned variables, one needs to set criteria on their discretization taking into account their values range. To this end, what follows is a justification of selection of three characteristics for each one of them: (a) minimum value, (b) maximum value and (c) the largest possible step they can obtain, which is defined as "Important Step" herein. This is not a straightforward task, however, one requires previous knowledge, either from theoretical models, or from experimental works, since the procedure of discretizing the variables is not a heuristic method.

Table 2. Indicative quality-affecting process parameters per process, along with minimum, maximum, and important-step values and alternatives calculation.

\begin{tabular}{|c|c|c|c|c|c|c|}
\hline Process & Material & Process Parameters & Min & Max & $\begin{array}{l}\text { Important } \\
\text { Step }\end{array}$ & $\begin{array}{c}\text { Alternatives } \\
(\operatorname{Max}-\mathrm{Min}+1) / \text { Step }\end{array}$ \\
\hline SLM [26] & Steel & Laser Power $(\mathrm{kW})$ & 1 & 10 & 0.1 & 100 \\
\hline FDM [67] & PLA & Heat Power (W) & 150 & 300 & 10 & 16 \\
\hline SLA [66] & Resin & Laser Power (mW) & 30 & 80 & 10 & 6 \\
\hline $\begin{array}{l}\text { Cement-based } \\
\text { AM [18] }\end{array}$ & Cement & $\begin{array}{l}\text { Extrusion/Head } \\
\text { Speed ratio }\end{array}$ & 0.55 & 2.5 & 0.5 & 6 \\
\hline
\end{tabular}


Table 3. Indicative quality key performance indicator (KPI) per process group along with minimum, maximum, important step values and alternatives calculation.

\begin{tabular}{|c|c|c|c|c|c|c|}
\hline Process & Material & Performance Indicators & Min & $\operatorname{Max}$ & $\begin{array}{l}\text { Important } \\
\text { Step }\end{array}$ & $\begin{array}{c}\text { Alternatives } \\
(\mathrm{Max}-\mathrm{Min}+1) / \text { Step }\end{array}$ \\
\hline SLM [26] & Steel & Temperature $\left({ }^{\circ} \mathrm{C}\right)$ & 700 & 1500 & 10 & 81 \\
\hline FDM [67] & PLA & Temperature $\left({ }^{\circ} \mathrm{C}\right)$ & 60 & 175 & 15 & 8 \\
\hline SLA [66] & Resin & Cure Depth $(\mathrm{mm})$ & 0.35 & 0.55 & 0.05 & 24 \\
\hline $\begin{array}{l}\text { Cement-based } \\
\text { AM [18] }\end{array}$ & Concrete & $\begin{array}{c}\text { Part consistency-quality } \\
\text { metric }\end{array}$ & 1 & 5 & 1 & 5 \\
\hline
\end{tabular}

For SLM, laser power has been selected as the process parameter because it is the most important in terms of defining the quality of a part due to the nature of the thermal-based process mechanism. The important step has been set to $0.1 \mathrm{~kW}$, the minimum value to $1 \mathrm{~kW}$, and the maximum to $10 \mathrm{~kW}$, leading to a total of 100 alternatives. For FDM, heating power has been selected as the process parameter because it is the most defining parameter of the heating-based process mechanism. Following the same procedure, 16 alternatives have been defined in FDM. In SLA, owing to the nature of the process mechanism (photopolymerization), the laser-power values are relatively low compared with the power values of the thermal AM process groups. In addition, it is noted that the difference between the minimum $(30 \mathrm{~mW})$ and maximum $(80 \mathrm{~mW})$ indicative values is not considerable in comparison to the important step. Finally, in concrete AM, the speed ratio of the head speed and the extrusion speed is the most important process parameter in terms of defining part quality. This decision is derived from the fact that if, according to the literature [21], one utilizes this ratio and the extrusion speed as two process parameters, instead of utilizing the two speeds, then the quality and the time as criteria are decoupled. Thus, the extrusion speed can be used as a tool for selecting the process time and the aforementioned ratio can be used as a control for quality. The important step is quite difficult to find, as by reviewing previous works it can be seen that the partitions in corresponding the ratio scale are non-linear [21]. For the sake of simplicity, though, an average value of 0.5 is adopted. In general, the process-parameter selection for the aforementioned processes, as well as the minimum and maximum values are supported by the extensive literature review that has been presented in a previous work by the present authors [18]. This is also the case for the important step, however, additional knowledge is needed, such as input from control performance [82].

In Table 3, an indicative quality-based KPI has been selected for the aforementioned processes, along with the most common minimum and maximum values and the important step. For SLM and FDM, the KPI of temperature has been selected because the process mechanism of these particular process groups utilizes heating for the joining of the consecutive layers. In SLA, exposure has been selected, as it characterizes the success of the polymerization-based process mechanism. In concrete AM, a heuristic measure for quality based on the consistency and uniformity of the path dimensions has been selected; this KPI is described in [21]. The important step for each KPI has been selected to enable a representative resolution for the corresponding phenomena of each process. Following a similar procedure to that of the process parameters, an indicative number of different alternatives has then been calculated for the KPIs as well. More specifically, 81 alternatives were calculated for SLM owing to the minimum of $700{ }^{\circ} \mathrm{C}$, maximum of $1500^{\circ} \mathrm{C}$ and important step of $10^{\circ} \mathrm{C}$, as the difference of the temperature limits of the mushy region (between solid and liquid) [29] results in this value. The difference between the two temperatures, divided by the important step results in 81 alternatives. The indicative alternatives of FDM were calculated to be 8 for a temperature range of $60-175^{\circ} \mathrm{C}$ and an important step of $15^{\circ} \mathrm{C}$. In SLA, which is not a thermal-based AM process, the nature of the process mechanism requires a constant exposure in order for the bonding to be successful. Therefore, the curing-depth KPI has been selected along with typical minimum and maximum depths. Finally, in concrete AM, the part consistency-quality metric (PCQM) has been selected as 
the most representative KPI. The PCQM is a qualitative empirical metric, reflecting the consistency and quality of the extruded part [21], in terms of extruded part width variation and roughness. It ranges from 1 (implying bad quality) to 5 (for high quality).

In Table 4, the joint Shannon entropy of the alternatives has been calculated for each process. For this calculation, the alternatives of the process parameters (Table 2) and of the KPIs (Table 3) of each process have been used based on the following equation:

$$
H(X, Y)=\frac{\log (X Y)}{\log (2)}
$$

where $H$ is the joint entropy of the process parameter $(X)$ and KPI $(Y)$ of each process. The results of this calculation yield the total entropy of each process joint with temperature, which is an indicative measure of motion complexity regarding its effect on part quality (Table 4).

Table 4. Process parameter (PP)-KPI coupled complexity.

\begin{tabular}{ccc}
\hline Process & Material & Total Entropy (bit) \\
\hline SLM & Steel & 13 \\
FDM & PLA & 7 \\
SLA & Resin & 8 \\
Cement-based AM & Concrete & 5 \\
\hline
\end{tabular}

These results indicate the complexity of the process mechanism regarding the impact of the process-parameter selections on the most representative quality-related KPIs. It may be observed that the indicative process of the metal-based AM group (SLM) has the highest value of process PP-KPI coupled complexity. It is followed by the indicative processes of the cement-based AM and plastic-based AM. The resin-based AM has the lowest total-entropy value, as there is a very strong PP-KPI connection and the best results are given when a strict relationship is maintained.

Another aspect of the process complexity that should be considered is the spatial complexity of the process mechanism. In thermal-based AM, the zone around the head is affected thermally (heat affected zone). These thermal gradients have an impact on part quality. In processes that use a different fusion mechanism, there is no such spatial differentiation that impacts part quality. Table 5 summarizes an indicative analysis of the aforementioned process groups concerning the spatial impact of the process mechanism and its complexity.

Table 5. Process-mechanism spatial complexity.

\begin{tabular}{|c|c|c|c|c|c|c|}
\hline Process & Material & $\begin{array}{c}\text { Process Mechanism } \\
\text { Spatially Indicative } \\
\text { Parameter }\end{array}$ & Min & Max & $\begin{array}{c}\text { Directly } \\
\text { Affected } \\
\text { Vicinity }(\mathrm{mm})\end{array}$ & $\begin{array}{c}\text { Total Entropy } \\
\text { (bit) }\end{array}$ \\
\hline SLM [26] & Steel & $\Delta \mathrm{T}\left({ }^{\circ} \mathrm{C}\right)$ & 300 & 1500 & 5 & 8 \\
\hline FDM [67] & PLA & $\Delta \mathrm{T}\left({ }^{\circ} \mathrm{C}\right)$ & 60 & 175 & 5 & 5 \\
\hline SLA [66] & Resin & - & & & & 0 \\
\hline Cement-based AM [18] & Concrete & - & & & & 0 \\
\hline
\end{tabular}

Indicative minimum and maximum temperatures that can simultaneously exist in a part during its manufacturing have been selected, along with the radius of the heat-affected zone. In SLM, owing to the high melting points of metals, there are significant temperature differences leading to intense thermal gradients. In FDM, this phenomenon is less intense owing to the lower melting point of the materials and the lower laser-power requirements. In SLA, although the fusion of the new layers is achieved via the use of a laser, the power is very low because the process mechanism is photopolymerization. Therefore, there are no 
significant temperature differences that would lead to thermal stresses and deformations. Finally, in cement-based AM, no spatial interaction occurs when the deposition of new material takes place. Table 6 lists the total complexity of the analyzed process groups.

Table 6. Total complexity.

\begin{tabular}{ccccc}
\hline Process & Material & PP-KPI Entropy (bit) & $\begin{array}{c}\text { Process-Mechanism } \\
\text { Spatial Complexity (bit) }\end{array}$ & Total Entropy (bit) \\
\hline SLM & Steel & 13 & 8 & 21 \\
FDM & PLA & 7 & 5 & 12 \\
SLA & Resin & 4 & 0 & 8 \\
Cement-based AM & Concrete & 7 & 0 & 5 \\
\hline
\end{tabular}

It may be observed that the highest complexity can be identified in metal-based AM (SLM), followed by plastic-based AM (FDM). The complexities of resin- and cement-based $\mathrm{AM}$ are the lowest. This indicates that the optimization required for the processes that utilize thermal-based process mechanisms is more complex: the values of the process parameters and the path sequence are more complicated and have a greater impact on part quality.

\section{Discussion}

\subsection{Classification of Processes}

As mentioned, the part size and the temperature could be used as criteria for process selection. The first one separates the mainly cement-based AM from the others, where the temperature is used as a classifier of the rest of them. As a matter of fact, in a draft quantified way, they seem to lie along a curve that resembles the equation Temperature $=$ a/Part size.

Therefore, as summarized in Figure 9, it may be observed that metal- and cementbased AM process groups are at the edges of the spectrum of the aforementioned parameters: Metal-based AM presents the highest temperature, very high complexity, and fine part size; the opposite is true for cement-based AM, as it presents low temperature and motion complexity and the largest part sizes. Subsequently, these two processes are ideal for the investigation of part quality focusing on the effect of the movement of the head. More specifically, in metal-based AM, the path component defines the gradients of the thermal field over time, which leads to the development of thermal stresses and deformations $[17,22]$. Moreover, metal-based AM processes feature the highest temperatures and some of the lowest part sizes. In contrast, in cement-based AM, the speed over time directly affects the dimensions and consistency of the deposited path because the process mechanism involves material flow from the head onto the machine platform [21]. The relatively large path dimensions compared with those of the layer further increase this effect. In addition, the process temperatures in cement-based AM are the lowest compared with those of all AM process groups, whereas the final part sizes are the largest. Finally, both the metal- and cement-based AM process groups attract ever-increasing industrial interest, while simultaneously, in both cases, there is a need for improvement of technical issues regarding part quality.

Furthermore, the (process) complexity, that is also related to modelling, can be introduced as an extra scale in this diagram, a third axis, in order to accommodate the fact that there are many more process parameters and many more performance indicators to take into account during modelling, as well as their mutual relationship complexity also varying. Once again, it seems that the metal- and cement-based AM process groups require completely different treatment (and effort) towards their performance prediction. 


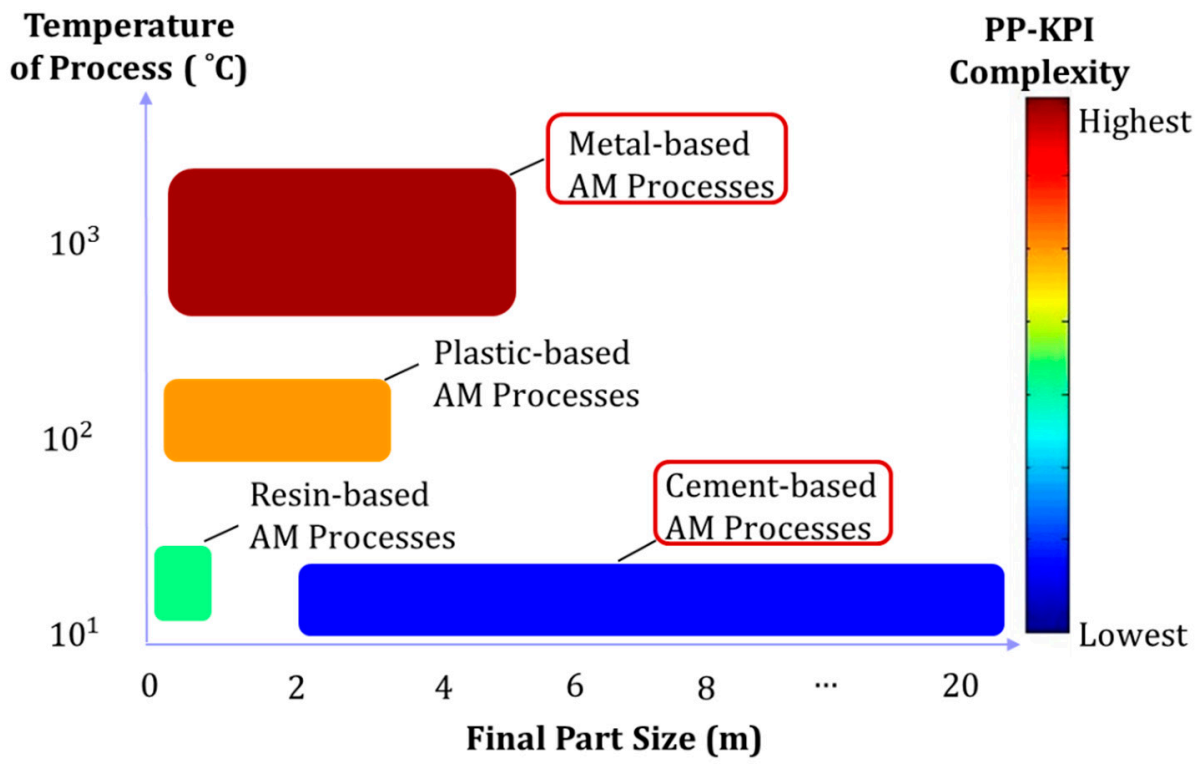

Figure 9. Classification of AM process groups.

The aforementioned facts make these two process groups ideal for the investigation of the effect of the head movement on part quality. Hence, the investigation of the effect of head path planning on quality has been performed by modeling metal-based AM [22]; meanwhile, the effect of speed on quality has been investigated by modeling cement-based AM [21].

\subsection{Connection to Modelling Procedure}

The modeling approach that corresponds to the principles of the proposed framework has to be in line with the basic concepts set by MBSE, i.e., aiming to bridge the gap between the different AM stakeholders. More specifically, such models promote the successful communication among the system development team, the design and production engineer, thus replacing the document-centric approach and minimizing the need for expensive and time-consuming experiments [83]. This is achieved by maintaining low computational costs and by introducing user-friendly metrics that reflect the impact of the decisions of the part designer, production engineer, tester, and user [21,22]. The result is a holistic modeling approach —enabling the simulation of the entire process time-which can be used by all the stakeholders for the evaluation of their decision-alternatives toward increased part quality and lower risk of failed parts. Moreover, important aspects of the AM process can be considered (effect of the movement of the head on part quality [21,22]) owing to the practical and close-to-the-process modeling approach. A more detailed description of the modeling approach will be presented below.

Summarizing, the classification of Figure 9 highlights the impact of each of the two components of the head movement (i.e., path and speed) on part quality for the different AM process groups. The additional parameters that have been used for this classification, beyond the complexity, are temperature of the process, and final part size. The process temperature and the final part size, inspired from classical classification [1] are parameters that are self-explanatory and can be easily quantified. The complexity is indicated by the coupling of the process parameter (PP) and the key performance indicator (KPI) of each AM process group.

It is noted that in thermal AM applications, the head path planning directly determines the profile of the thermal field of the part, which drives the development of thermal stresses and deformations: high temperature gradients lead to increased thermal stresses and deformations [84]. Due to the fact that the thermal phenomena that take place in AM processes are highly dynamic in time and space [27], the existing thermal models are disadvantaged by their very high computational cost in terms of time and memory 
requirements [17]. Toward the improvement of the practicality of modeling and simulations, the Stress Formation Tendency Index (SFTI) has been developed and used. SFTI encapsulates the intensity of the non-uniformity of the thermal field, which is responsible for the development of thermal stresses and deformations [84]. Therefore, conclusions concerning process-parameter and head path planning selections are drawn from the thermal field, which is significantly faster in its calculation than the thermally induced stresses and deformations [22].

Regarding the investigation of the head speed on part quality in the cement-based AM process group, the empirical modeling approach would better be followed because it was best suited for the investigation of the KPIs and process parameters involved (as per the extensive literature review [18]). The effects of controlling the path width on the quality were investigated in the manner that the path width was controlled by changing the head speed, while maintaining the extrusion speed (material flow) constant [21]. This resulted in a change in the ratio of the aforementioned speeds which is the main factor of the changes in the width of the deposited path. The advantage of this approach is its higher precision and productivity because the response time of the head is faster than that of the extrusion-head system for large-scale cement-based AM applications [85].

\subsection{Subjectivity and Limitations of the Heuristic Entropic Metric}

It is inevitable that some parameters that are taken into consideration may be subjective and that the heuristic entropic metric taking into account the discretized variables may not be an appropriate. In particular, given that $A$ may be the maximum value of a variable, $B$ its minimum value and $C$ the corresponding important step, the entropy of this variable is given by $X$ of Equation (7).

$$
X=\frac{\log \frac{A-B}{C}}{\log (2)}
$$

Therefore, to study the subjectivity of this metric, one should transform the metric as a function of the $\xi=\Delta / C$ quantity, where $\Delta=A-B$. Thus, it is the order of magnitude between the important step and the variable extreme values that signifies how this function behaves. As a matter of fact, if $\xi$ is approximately equal to 1 , then the metric is very close to zero. If, on the other hand, $\xi$ is approximately equal to 10 , then, about 7 bits are needed to describe the combinations. Therefore, as an attempt to study bias with respect to variables, and indicatively for the case of temperature-related complexity, the difference of SLM and FDM entropies is considered (Equation (8)), taking into account the (rather arbitrary) values appearing in Table 7 for the corresponding important steps. It can be observed that FDM has smaller Important Step values, to compensate for the lower temperature extreme values.

$$
\Delta X=\frac{\log \frac{1500-700+1}{C_{S L M}}}{\log (2)}-\frac{\log \frac{175-60+1}{C_{F D M}}}{\log (2)}
$$

Table 7. Difference between SLM and FDM entropies for the cases of temperature. A positive value means that, for that specific combination of important steps C, SLM is more complex. A negative value means that FDM is more complex.

\begin{tabular}{cccccc}
\hline FDM $\backslash$ SLM & $C_{S L M}=\mathbf{1 0}$ & $C_{S L M}=\mathbf{1 0 0}$ & $C_{S L M}=\mathbf{2 0 0}$ & $C_{S L M}=\mathbf{5 0 0}$ & $C_{S L M}=\mathbf{1 0 0 0}$ \\
\hline$C_{F D M}=0.1$ & 3 & 0 & -2 & -3 & -4 \\
$C_{F D M}=1$ & 7 & 3 & 1 & 0 & -1 \\
$C_{F D M}=2$ & 8 & 4 & 2 & 1 & 0 \\
$C_{F D M}=5$ & 9 & 6 & 3 & 2 & 1 \\
$C_{F D M}=10$ & 10 & 7 & 4 & 3 & 2 \\
\hline
\end{tabular}

Agnostically, simply by estimating the average of the occurring values, the mean value of the entropies difference is equal to almost 3 bits, not too far from the actual difference of 4 bits that occurs once one uses the important steps of Table 3 . This could be an indication 
that the intrinsic complexity of SLM is larger than that of FDM. In any case, these numerical examples are only indicative. After all, the $\xi$ ratio of each process seems to be the key to this path and the values for extremes as well as the important ratio were based on sophisticated guesses, based on specific functionalities, as justified above. Additionally, as information is aggregated with respect to the process mechanism, it seems that this difference is increasing, leading to rather safe conclusions on the classification of the processes with respect to their complexity.

\section{Conclusions}

To summarize, a heuristic metric for the complexity of a process has been suggested and applied in the case of various AM processes. This metric has been proved to be quite useful towards forming a metamodeling framework for processes that includes the machine aspect (i.e., through path and speed selection) on attributes/performance indicators (i.e., part quality). In particular, all the goals towards successful AM modeling are summarized in the following points and can be facilitated through the current framework:

- Development of process models for the increase in AM part quality;

- Consideration and investigation of the effect of the head movement on part quality (path and speed);

- Increase in the practicality of simulations for AM;

- Enabling the practical evaluation of alternatives to achieve higher part quality;

- Achieving the simulation of the entire process time.

In particular, the path of the head directly affects the thermal gradients by inducing thermal stresses and deformations. Thus, the general principles concerning head path planning that have been drawn from the investigation conducted on metal-based AM can be applied to the remaining thermal-based AM processes, such as plastic-based PBF (FDM). Also, for the AM process groups that there is material flow from the head to the machine platform, coordination between the flow rate and the change in speed is required in order to maintain part quality. In such a case, the conclusions drawn in both cases are applicable and should be considered. It should be noted that the control of the energy flow (i.e., change in laser power) has a faster response rate; thus it is easier to be achieved than the control of the flow of the material. In addition, the response rate becomes lower for greater flows from nozzles of larger diameters.

Moreover, it can be concluded easily that in the case of direct energy deposition, the complexity is even higher, thus more elaborated modelling should be performed. The reason is that the flow of the powder itself is an extra process parameter that has to be taken into consideration.

Finally, as far as the practicality of the modelling procedure in industrial applications is concerned, MBSE could benefit from such metrics, as the added value of a model that can be adapted to different levels of detail could be based on such metrics. For instance, the model development time can be predicted through such a complexity metric. Then, by comparing this time against the monetary benefits derived from the corresponding modelling, i.e., due to zero-defect policies, one could decide on what level of detail to adopt.

Regarding future work, metamodeling frameworks need to keep being enhanced, so that both conceptual and mathematical modeling are facilitated; the key concept seems to be that of level-of-detail, so everything has to be performed in accordance to MBSE and hierarchical modelling. Also, it has to be mentioned that metrics need to include somehow the complexity of the equations, without neglecting the function $\eta$ above in Section 5 . Potentially, the solution times of the models as well as the dimensionless constants could be integrated to this end. This direction will help also towards achieving further aspects of practicality, since a more accurate in-advance estimation of modelling development time would be achieved. 
Author Contributions: Conceptualization, A.P. and P.S.; methodology, A.P.; formal analysis, P.F.; writing —original draft preparation, P.F.; writing—review and editing, A.P. and P.S. All authors have read and agreed to the published version of the manuscript.

Funding: This work is conducted under the framework of EU Project AVANGARD. This project has received funding from the European Union's Horizon 2020 research and innovation program under grant agreement No 869986. The dissemination of results herein reflects only the authors' view and the Commission is not responsible for any use that may be made of the information it contains.

Institutional Review Board Statement: Not applicable.

Informed Consent Statement: Not applicable.

Data Availability Statement: Not applicable.

Conflicts of Interest: The authors declare no conflict of interest. The funders had no role in the design of the study; in the collection, analyses, or interpretation of data; in the writing of the manuscript, or in the decision to publish the results.

\section{References}

1. Chryssolouris, G. Manufacturing Systems: Theory and Practice, 2nd ed.; Springer: New York, NY, USA, 2006; ISBN 0387256830.

2. Saptarshi, S.M.; Zhou, C. Basics of 3D printing: Engineering aspects. 3D Print. Orthop. Surg. 2019, 17-30. [CrossRef]

3. Levy, G.N.; Schindel, R.; Kruth, J.P. Rapid manufacturing and rapid tooling with layer manufacturing (LM) technologies, state of the art and future perspectives. CIRP Ann. 2003, 52, 589-609. [CrossRef]

4. Hopkinson, N.; Hague, R.J.M.; Dickens, P.M. Rapid Manufacturing: An Industrial Revolution for the Digital Age; John Wiley \& Sons, Ltd.: Chichester, UK, 2005; ISBN 9780470033999.

5. Marga, F.; Jakab, K.; Khatiwala, C.; Shepherd, B.; Dorfman, S.; Hubbard, B.; Colbert, S.; Gabor, F. Toward engineering functional organ modules by additive manufacturing. Biofabrication 2012, 4, 22001. [CrossRef]

6. Bikas, H.; Lianos, A.; Stavropoulos, P. A design framework for additive manufacturing. Int. J. Adv. Manuf. Technol. 2019, 103, 3769-3783. [CrossRef]

7. Wohlers, T.T.; Caffrey, T. Wohlers Report 2015: 3D Printing and Additive Manufacturing State of the Industry Annual Worldwide Progress Report; Wohlers Associates: Fort Collins, CO, USA, 2015; ISBN 0991333217.

8. Thomas, D. Costs, benefits, and adoption of additive manufacturing: A supply chain perspective. Int. J. Adv. Manuf. Technol. 2016, 85, 1857-1876. [CrossRef] [PubMed]

9. Bikas, H.; Stavropoulos, P.; Chryssolouris, G. Additive manufacturing methods and modelling approaches: A critical review. Int. J. Adv. Manuf. Technol. 2015, 83, 389-405. [CrossRef]

10. Stavropoulos, P.; Papacharalampopoulos, A.; Michail, C.; Vassilopoulos, V.; Alexopoulos, K.; Perlo, P. A two-stage decision support system for manufacturing processes integration in microfactories for electric vehicles. Procedia Manuf. 2021, 54, 106-111. [CrossRef]

11. Chan, S.L.; Lu, Y.; Wang, Y. Data-driven cost estimation for additive manufacturing in cybermanufacturing. J. Manuf. Syst. 2018, 46, 115-126. [CrossRef]

12. Adam, G.; Zimmer, D. Design for Additive Manufacturing-Element transitions and aggregated structures. CIRP J. Manuf. Sci. Technol. 2014, 7, 20-28. [CrossRef]

13. Levy, G.N. The role and future of the Laser Technology in the Additive Manufacturing environment. Phys. Procedia 2010, 5, 65-80. [CrossRef]

14. ISO/ASTM52900-15. Standard Terminology for Additive Manufacturing—General Principles—Terminology; ASTM International: West Conshohocken, PA, USA, 2015.

15. Hegab, H. Design for additive manufacturing of composite materials and potential alloys: A review. Manuf. Rev. 2016, 3, 11. [CrossRef]

16. Bartolo, P.; Kruth, J.-P.; Silva, J.; Levy, G.; Malshe, A.; Rajurkar, K.; Mitsuishi, M.; Ciurana, J.; Leu, M. Biomedical production of implants by additive electro-chemical and physical processes. CIRP Ann. 2012, 61, 635-655. [CrossRef]

17. Gibson, I.; Rosen, D.W.; Stucker, B. Additive Manufacturing Technologies; Springer US: Boston, MA, USA, $2010 ;$ ISBN 9781441911193.

18. Stavropoulos, P.; Foteinopoulos, P. Modelling of additive manufacturing processes: A review and classification. Manuf. Rev. 2018, 5, 2. [CrossRef]

19. Kempen, K.; Vrancken, B.; Buls, S.; Thijs, L.; van Humbeeck, J.; Kruth, J.-P. Selective Laser Melting of Crack-Free High Density M2 High Speed Steel Parts by Baseplate Preheating. J. Manuf. Sci. Eng. 2014, 136, 061026. [CrossRef]

20. Flatt, R.J.; Wangler, T. Editorial for special issue on digital concrete. Cem. Concr. Res. 2018, 112, 1-4. [CrossRef]

21. Foteinopoulos, P.; Esnault, V.; Komineas, G.; Papacharalampopoulos, A.; Stavropoulos, P. Cement-based additive manufacturing: Experimental investigation of process quality. Int. J. Adv. Manuf. Technol. 2020, 106, 4815-4826. [CrossRef]

22. Foteinopoulos, P.; Papacharalampopoulos, A.; Angelopoulos, K.; Stavropoulos, P. Development of a simulation approach for laser powder bed fusion based on scanning strategy selection. Int. J. Adv. Manuf. Technol. 2020, 108, 3085-3100. [CrossRef] 
23. Hu, D.; Kovacevic, R. Modelling and measuring the thermal behaviour of the molten pool in closed-loop controlled laser-based additive manufacturing. Proc. Inst. Mech. Eng. Part B J. Eng. Manuf. 2003, 217, 441-452. [CrossRef]

24. Li, Y.; Gu, D. Parametric analysis of thermal behavior during selective laser melting additive manufacturing of aluminum alloy powder. Mater. Des. 2014, 63, 856-867. [CrossRef]

25. Roberts, I.; Wang, C.; Esterlein, R.; Stanford, M.; Mynors, D.J. A three-dimensional finite element analysis of the temperature field during laser melting of metal powders in additive layer manufacturing. Int. J. Mach. Tools Manuf. 2009, 49, 916-923. [CrossRef]

26. Zhang, D.Q.; Cai, Q.Z.; Liu, J.H.; Zhang, L.; Li, R.D. Select laser melting of W-Ni-Fe powders: Simulation and experimental study. Int. J. Adv. Manuf. Technol. 2010, 51, 649-658. [CrossRef]

27. Song, B.; Dong, S.; Liao, H.; Coddet, C. Process parameter selection for selective laser melting of Ti6Al4V based on temperature distribution simulation and experimental sintering. Int. J. Adv. Manuf. Technol. 2012, 61, 967-974. [CrossRef]

28. Yin, J.; Zhu, H.; Ke, L.; Lei, W.; Dai, C.; Zuo, D. Simulation of temperature distribution in single metallic powder layer for laser micro-sintering. Comput. Mater. Sci. 2012, 53, 333-339. [CrossRef]

29. Foteinopoulos, P.; Papacharalampopoulos, A.; Stavropoulos, P. On thermal modeling of Additive Manufacturing processes. CIRP J. Manuf. Sci. Technol. 2018, 20, 66-83. [CrossRef]

30. Deloitte. Challenges of Additive Manufacturing: Why Companies Don't Use Additive Manufacturing in Serial Production. Available online: https://www2.deloitte.com/content/dam/Deloitte/de/Documents/operations/Deloitte_Challenges_of_ Additive_Manufacturing.pdf (accessed on 23 July 2021).

31. Durakovic, B. Design for additive manufacturing: Benefits, trends and challenges. Period. Eng. Nat. Sci. (PEN) 2018, 6, 179-191. [CrossRef]

32. Giberti, H.; Sbaglia, L.; Silvestri, M. Mechatronic Design for an Extrusion-Based Additive Manufacturing Machine. Machines 2017, 5, 29. [CrossRef]

33. Ford, S.; Despeisse, M. Additive manufacturing and sustainability: An exploratory study of the advantages and challenges. $J$. Clean. Prod. 2016, 137, 1573-1587. [CrossRef]

34. Ngo, T.D.; Kashani, A.; Imbalzano, G.; Nguyen, K.T.Q.; Hui, D. Additive manufacturing (3D printing): A review of materials, methods, applications and challenges. Compos. Part B Eng. 2018, 143, 172-196. [CrossRef]

35. Tofail, S.A.M.; Koumoulos, E.P.; Bandyopadhyay, A.; Bose, S.; O’Donoghue, L.; Charitidis, C. Additive manufacturing: Scientific and technological challenges, market uptake and opportunities. Mater. Today 2018, 21, 22-37. [CrossRef]

36. Salehi, V.; Wang, S. Munich Agile MBSE Concept (MAGIC). In Proceedings of the Design Society: International Conference on Engineering Design, Delft, The Netherlands, 5-8 August 2019; Cambridge University Press: Cambridge, UK, 2019; Volume 1, pp. 3701-3710. [CrossRef]

37. Müller, S.; Westkämper, E. Modelling of Production Processes: A Theoretical Approach to Additive Manufacturing. Procedia CIRP 2018, 72, 1524-1529. [CrossRef]

38. Michopoulos, J.G.; Iliopoulos, A.P.; Steuben, J.C.; Birnbaum, A.J.; Lambrakos, S.G. On the multiphysics modeling challenges for metal additive manufacturing processes. Addit. Manuf. 2018, 22, 784-799. [CrossRef]

39. Topczak, M.; Śliwa, M. Assessment of the possibility of using Bayesian nets and Petri nets in the process of selecting additive manufacturing technology in a manufacturing company. Appl. Comput. Sci. 2021, 17, 5-16. [CrossRef]

40. Belkadi, F.; Sanfilippo, E.; Bernard, A.; Vidal, L. A Product-Process Model for Decision-Aid Perspective in Additive Manufacturing Field. Comput. Aided Des. Appl. 2020, 17, 1278-1293. [CrossRef]

41. Afrasiabi, M.; Lüthi, C.; Bambach, M.; Wegener, K. Multi-Resolution SPH Simulation of a Laser Powder Bed Fusion Additive Manufacturing Process. Appl. Sci. 2021, 11, 2962. [CrossRef]

42. De Baere, D.; Moshiri, M.; Mohanty, S.; Tosello, G.; Hattel, J.H. Numerical Investigation into the Effect of Different Parameters on the Geometrical Precision in the Laser-Based Powder Bed Fusion Process Chain. Appl. Sci. 2020, 10, 3414. [CrossRef]

43. Bian, P.; Shao, X.; Du, J. Finite Element Analysis of Thermal Stress and Thermal Deformation in Typical Part during SLM. Appl. Sci. 2019, 9, 2231. [CrossRef]

44. Letenneur, M.; Kreitcberg, A.; Brailovski, V. Optimization of Laser Powder Bed Fusion Processing Using a Combination of Melt Pool Modeling and Design of Experiment Approaches: Density Control. JMMP 2019, 3, 21. [CrossRef]

45. Westbeek, S.; Remmers, J.J.C.; van Dommelen, J.A.W.; Geers, M.G.D. Multi-scale process simulation for additive manufacturing through particle filled vat photopolymerization. Comput. Mater. Sci. 2020, 180, 109647. [CrossRef]

46. Pateloup, V.; Michaud, P.; Chartier, T. Optimization of part orientation and adapted supports for manufacturing of ceramic parts by stereolithography using finite element simulations. Open Ceram. 2021, 6, 100132. [CrossRef]

47. Roussel, N.; Spangenberg, J.; Wallevik, J.; Wolfs, R. Numerical simulations of concrete processing: From standard formative casting to additive manufacturing. Cem. Concr. Res. 2020, 135, 106075. [CrossRef]

48. Comminal, R.; Leal da Silva, W.R.; Andersen, T.J.; Stang, H.; Spangenberg, J. Modelling of 3D concrete printing based on computational fluid dynamics. Cem. Concr. Res. 2020, 138, 106256. [CrossRef]

49. Gopsill, J.A.; Shindler, J.; Hicks, B.J. Using finite element analysis to influence the infill design of fused deposition modelled parts. Prog. Addit. Manuf. 2018, 3, 145-163. [CrossRef]

50. Tao, F.; Bi, L.; Zuo, Y.; Nee, A.Y.C. A Cooperative Co-Evolutionary Algorithm for Large-Scale Process Planning With Energy Consideration. J. Manuf. Sci. Eng. 2017, 139, 061016. [CrossRef] 
51. Jiang, J.; Xu, X.; Stringer, J. Optimization of process planning for reducing material waste in extrusion based additive manufacturing. Robot. Comput. Integr. Manuf. 2019, 59, 317-325. [CrossRef]

52. Tapia, G.; Khairallah, S.; Matthews, M.; King, W.; Elwany, A. Gaussian process-based surrogate modeling framework for process planning in laser powder-bed fusion additive manufacturing of 316L stainless steel. Int. J. Adv. Manuf. Technol. 2018, 94, 3591-3603. [CrossRef]

53. Priarone, P.; Ingarao, G. Towards criteria for sustainable process selection: On the modelling of pure subtractive versus additive/subtractive integrated manufacturing approaches. J. Clean. Prod. 2017, 144, 57-68. [CrossRef]

54. Zielinski, J.; Vervoort, S.; Mindt, H.-W.; Megahed, M. Influence of Powder Bed Characteristics on Material Quality in Additive Manufacturing. Berg Huettenmaenn Mon. 2017, 162, 192-198. [CrossRef]

55. Knapp, G.L.; Mukherjee, T.; Zuback, J.S.; Wei, H.L.; Palmer, T.A.; De, A.; DebRoy, T. Building blocks for a digital twin of additive manufacturing. Acta Mater. 2017, 135, 390-399. [CrossRef]

56. Duflou, J.R.; Sutherland, J.W.; Dornfeld, D.; Herrmann, C.; Jeswiet, J.; Kara, S.; Hauschild, M.; Kellens, K. Towards energy and resource efficient manufacturing: A processes and systems approach. CIRP Ann. 2012, 61, 587-609. [CrossRef]

57. Ning, J.; Sievers, D.E.; Garmestani, H.; Liang, S.Y. Analytical modeling of in-process temperature in powder feed metal additive manufacturing considering heat transfer boundary condition. Int. J. Precis. Eng. Manuf. Green Tech. 2020, 7, 585-593. [CrossRef]

58. Choi, Y.-H.; Kim, C.-M.; Jeong, H.-S.; Youn, J.-H. Influence of Bed Temperature on Heat Shrinkage Shape Error in FDM Additive Manufacturing of the ABS-Engineering Plastic. WJET 2016, 4, 186-192. [CrossRef]

59. Moini, M.; Olek, J.; Youngblood, J.P.; Magee, B.; Zavattieri, P.D. Additive Manufacturing and Performance of Architectured Cement-Based Materials. Adv. Mater. 2018, 30, e1802123. [CrossRef]

60. Hällgren, S.; Pejryd, L.; Ekengren, J. (Re)Design for Additive Manufacturing. Procedia CIRP 2016, 50, 246-251. [CrossRef]

61. Langnau, L. What Is the Maximum Size Build for an Additive Manufacturing System? Make Parts Fast [Online], April 82020. Available online: https:/ / www.makepartsfast.com/what-is-the-maximum-size-build-for-an-additive-manufacturing-system/ (accessed on 5 July 2021).

62. Robinson, S. Conceptual modelling for simulation Part I: Definition and requirements. J. Oper. Res. Soc. 2008, 59, 278-290. [CrossRef]

63. Blomhoj, M. Developing mathematical modelling competence: Conceptual clarification and educational planning. Teach. Math. Appl. 2003, 22, 123-139. [CrossRef]

64. Liu, C.; Le Roux, L.; Körner, C.; Tabaste, O.; Lacan, F.; Bigot, S. Digital Twin-enabled Collaborative Data Management for Metal Additive Manufacturing Systems. J. Manuf. Syst. 2020, in press. [CrossRef]

65. Mourtzis, D. Simulation in the design and operation of manufacturing systems: State of the art and new trends. Int. J. Prod. Res. 2020, 58, 1927-1949. [CrossRef]

66. Barclift, M.; Williams, C. Examining variability in the mechanical properties of parts manufactured via polyjet direct 3D printing. In International Solid Freeform Fabrication Symposium; University of Texas at Austin Austin: Austin, TX, USA, 2012 ; pp. 6-8.

67. Mowshowitz, A. Entropy and the complexity of graphs: I. An index of the relative complexity of a graph. Bull. Math. Biophys. 1968, 30, 175-204. [CrossRef] [PubMed]

68. Papacharalampopoulos, A. Investigating Data-Driven Systems as Digital Twins: Numerical Behavior of Ho-Kalman Method for Order Estimation. Processes 2020, 8, 431. [CrossRef]

69. Mellor, S.; Clark, T.; Futagami, T. Model-Driven Development: Guest editors' introduction. IEEE Softw. 2003, 20, 14-18. [CrossRef]

70. Edmonds, B. Complexity and scientific modelling. Found. Sci. 2000, 5, 379-390. [CrossRef]

71. Bullen, N.; Jones, K.; Duncan, C. Modelling Complexity: Analysing Between-Individual and Between-Place Variation-A Multilevel Tutorial. Environ. Plan A 1997, 29, 585-609. [CrossRef]

72. Badii, R.; Politi, A. Complexity: Hierarchical Structures and Scaling in Physics; Cambridge University Press: Cambridge, UK, 1999; ISBN 0521663857.

73. Kaltsoukalas, K.; Makris, S.; Chryssolouris, G. On generating the motion of industrial robot manipulators. Robot. Comput. Integr. Manuf. 2015, 32, 65-71. [CrossRef]

74. Lim, S.; Buswell, R.A.; Le, T.T.; Austin, S.A.; Gibb, A.G.F.; Thorpe, T. Developments in construction-scale additive manufacturing processes. Autom. Constr. 2012, 21, 262-268. [CrossRef]

75. Stavridis, J.; Papacharalampopoulos, A.; Stavropoulos, P. Quality assessment in laser welding: A critical review. Int. J. Adv. Manuf. Technol. 2018, 94, 1825-1847. [CrossRef]

76. Wach, R.; Wolszczak, P.; Adamus-Wlodarczyk, A. Enhancement of Mechanical Properties of FDM-PLA Parts via Thermal Annealing. Macromol. Mater. Eng. 2018, 303, 1800169. [CrossRef]

77. Uzcategui, A.C.; Muralidharan, A.; Ferguson, V.L.; Bryant, S.J.; McLeod, R.R. Understanding and Improving Mechanical Properties in 3D printed Parts Using a Dual-Cure Acrylate-Based Resin for Stereolithography. Adv. Eng. Mater. 2018, 20, 1800876. [CrossRef] [PubMed]

78. Papacharalampopoulos, A.; Giannoulis, C.; Stavropoulos, P.; Mourtzis, D. A Digital Twin for Automated Root-Cause Search of Production Alarms Based on KPIs Aggregated from IoT. Appl. Sci. 2020, 10, 2377. [CrossRef]

79. Prasad, D.; Jayswal, S.C. Scheduling in reconfigurable manufacturing system for uncertainty in decision variables. Mater. Today Proc. 2018, 5, 18451-18458. [CrossRef] 
80. Papacharalampopoulos, A.; Bikas, H.; Stavropoulos, P. Path planning for the infill of 3D printed parts utilizing Hilbert curves. Procedia Manuf. 2018, 21, 757-764. [CrossRef]

81. Bos, F.; Wolfs, R.; Ahmed, Z.; Salet, T. Additive manufacturing of concrete in construction: Potentials and challenges of 3D concrete printing. Virtual Phys. Prototyp. 2016, 11, 209-225. [CrossRef]

82. Stavropoulos, P.; Papacharalampopoulos, A.; Michail, C.K.; Chryssolouris, G. Robust Additive Manufacturing Performance through a Control Oriented Digital Twin. Metals 2021, 11, 708. [CrossRef]

83. Friedenthal, S.; Griego, R.; Sampson, M. INCOSE model based systems engineering (MBSE) initiative. INCOSE 2007 Symp. 2007, $11,1-29$.

84. Kruth, J.-P.; Levy, G.; Klocke, F.; Childs, T.H.C. Consolidation phenomena in laser and powder-bed based layered manufacturing. CIRP Ann. 2007, 56, 730-759. [CrossRef]

85. HINDCON EU Project. Hybrid INDustrial CONstruction through A 3D Printing "All-in-One" Machine for Large-Scale Advanced Manufacturing and Building Processes. Available online: https:/ / cordis.europa.eu/project/id/723611 (accessed on 2 June 2021). 